\title{
Original article \\ EFFECT OF CONTINOUS LIGHT AND DARKNESS EXPOSURES ON THE PITUITARY-GONADAL AXIS AND THYROID ACTIVITY IN MALE RATS
}

\author{
I. I. OLATUNJI-BELLO* AND O. A. SOFOLA \\ Department of Physiology, College of Medicine, University of Lagos. Lagos, Nigeria.
}

\begin{abstract}
The effects of constant light and dark exposure of pubertal male rats on the pituitary-gonadal axis and thyroid activity were studied. The indices of thyroid activity were weight of the thyroid gland, estimation of serum levels of thyroxine $\left(T_{4}\right)$ by radioimmunoassay (RIA) technique and histological studies of the thyroid gland. The indices of gonadal activity chosen were weight and histological study of the testes and determination of serum levels of Luteinizing hormone (LH) and Follicle Stimulating Hormon (FSH) by RIA technique. In the rats exposed to continuous light, the weight of the thyroid gland increased significantly $(P<0.02)$ and the serum level of $T_{4}$ also increased significantly $(P<0.02)$. The histological observations revealed thyroid follicles that were sparsely filled with colloid while the epithelial cells were more columnar, evidence of increased glandular activity. The size of the testes increased significantly $(P<0.001)$. The serum level of FSH was increased significantly $(P<0.001)$ while there was a slight rise in the serum level of LH. Histological observations in the testes showed that the seminiferous tubules were well spaced out and appeared to contain more spermatozoa when compared with the control. In the rats exposed to constant darkness, the weight of the thyroid gland was significantly lower $(P<0.02)$ when compared with that of the control. The serum level of $T_{4}$ remained unchanged while histological examination of the thyroid gland showed the follicles containing less colloid and the epithelial cells appearing more columnar when compared with the control. The weight of the testes was markedly reduced $(P<0.001)$. The serum level of $L H$ was reduced significantly $(P<0.05)$ while there was a slight fall in the serum level of FSH. The histological examination of the testes showed that the, seminiferous tubules clustered together and contained little or no spermatozoa. When compared with the rats that were exposed to normal lighting rhythm, continuous darkness exposure resulted in a decrease in the thyroid activity as well as a marked decrease in gonadal activity in male rats.
\end{abstract}

KEYWORDS: Pineal, melatonin, thyroid gland, gonadal function, light, darkness

*Address for correspondence: yemibello@lycos.com

\section{INTRODUCTION}

In animals that inhabit progressively higher altitudes where the extremes of day-length, temperature and food availability are especially obvious, circannual rhythms in physiology are particularly apparent (Reiter, 1991a).

Mammals, which utilize environmental lighting information to appraise their internal organs of the season, are described as photoperiodic, and perhaps most mammals are in this category, to varying degrees (Reiter, 1991c). Photoperiod-sensitive mammals depend on the retinas to provide the brain with information about seasonally changing day-lengths. It is however, the pineal gland, an end organ of the visual system, which translate the photoperiodic message in a chemical signal which serves as a messenger to every organ in the body (Reiter, 1991c). Melatonin is produced in vertebrate pineal gland at night and thus serves as the chemical expression of darkness (Reiter, 1991b).

An area in which the pineal gland has a relatively well-defined characterized function is in the control of gonadal responses to environmental light (Reiter, 1994). When most mammals are exposed to continuous light or darkness or are blinded, marked changes occur in the timing of gonadal maturation and in the subsequent ovulatory cycles. Blind humans exhibit a significant acceleration of menarche, blinded rats show the opposite response reference. Hamsters kept in continuous darkness develop a pronounced atrophy of the gonads and delayed growth of accessory sex organs secondary to testosterone deficiency (Wade and Bartness, 1984). These effects are completely reversed by pinealectomy indicating that darkness has generated some kind of pineal signal (Rollag and Stetson, 1986).
Studies of thyroid physiology in rats support the view that the pineal gland has an anti-thyrotropic action. Studies reported by Vriend (I 981) showed that chronic exposure of hamsters to short photo-period, darkness or blindness resulted in a depression of plasma thyroxine and thyrotropin (TSH) Removal of the pineal gland, which synthesizes melatonin, prevented these effects (Vriend, 198 1). Continuous exposure to eight lends to a complete suppression of melatonin release reference.

\section{MATERIALS AND METHODS}

A total of fifteen (15) male pubertal rats were used in this study. The animals were divided into three groups of five rats each. Each group was made up of the following: Group 1 - Normal or control rats; Group 2 Rats exposed to continuous light; Group 3 - Rats exposed to continous darkness. The control rats were the normal rats that were kept in the departmental animal room that had a normal lighting rhythm of 12 hours light and 12 hours of darkness. This was achieved by switching on the light at 7.00 in the morning and off at 7.00 in the evening. The rats exposed to constant light were housed in a small room in the Department of Physiology, University of Lagos. This room was illuminated with four feet (4ft) fluorescent lamps that gives a mimicked natural daylight, and switched on permanently for over 4 weeks covering the duration of the experiment. The rats exposed to constant darkness were housed in a small room that had its windows covered with a black cotton material. They were exposed to only a few minutes of candlelight (23 minutes) per day when food in the cages was being replaced and the cages were cleaned. Small gaps 
between the door leading to the dark corridor allowed adequate amount of aeration..

The animals were kept in their respective environment for a minimum period of 4 weeks. After this period of exposure, the rats were stunned by cervical dislocation. After this, the rats were placed in a supine position, The thorax and abdomen were cut open. Using a 22-gauge needle attached to a $2 \mathrm{ml}$ syringe, 3 millilitres of cardiac blood was collected and allowed to clot at room temperature. The blood samples were later centrifuged at 3,000 rpm for 30 minutes. At the end of this period, the supernatants (sera) were carefully pippetted and put into small, labeled sample tubes. The sera were stored in the freezer at $-20^{\circ} \mathrm{C}$ until they were ready for radioimmunoassay.

Immediately after the withdrawal of blood from the heart, the neck region of the rat was opened, the trachea and the thyroid gland were exposed. The thyroid gland was removed by cutting out the trachea and the thyroid gland attached. The thyroid gland was neatly and carefully teased off the trachea using fine dissecting forceps, weighed on Sarton'ous balance (Sartorious Werke GMRH Gottingen Model 2474, Germany) and then kept in a solution of formal saline for at least 24 hours. The scrotal sacs of the animals were dissected open and the pair of testes and epididymides were exposed. The epididymis was neatly teased out by fine dissection, free from the testis and the testis was weighed. The testis was weighed using the Mettler balance (Mettler P I 200/120ON Mettler Instruments AG Zurich,Switzerland). The weights were recorded and expressed as milligramme'per gramme body weight (mg/g body wt.) of rat.

After weighing all organs and glands, they were kept in a $10 \%$ solution of formal saline fixative. The testes and the thyroid glands were later dehydrated in absolute in alcohol, embedded in paraffin wax and then cut into thin sections $(5 \mu \mathrm{m})$ using a microtome. These sections were mounted on clean glass slides and then stained with haematoxylin and eosin. The sections were viewed under the light microscope at times 10 and times 40 magnifications in order to observe any changes in the structure of the tissue. The Amerlex MT4, MFSH and MLH RIA kits were used for the radioimmunoassay studies (Kodak Clinical Diagnostics Ltd., Amersham, Buckinghamshire, Engand). The instructions in the booklet that accompanied each kit were followed carefully for the preparation of standard curve and the determination of hormone levels using the gammacounter. The standard curves were plotted and the values of the serum levels of each hormone in the samples were determined by extrapolating the counts of each sample to the standard curve. Duplicate analyses were performed on each sample.

Statistical Analysis: All results presented in this study are expressed as mean \pm standard error of the mean (mean \pm S.E.M). The level of statistical significance was determined by the Student's t-test.

\section{RESULT}

Thyroid and Tesicular weights in light and dark exposed rats: The mean weight of the thyroid gland in rats exposed to continuous light was $0.206 \pm 0.01 \mathrm{mg} / \mathrm{g}$ body weight, which was $47.14 \%$ greater than that of the control $(0.14 \pm 0.13 \mathrm{mg} / \mathrm{g}$ body weight; $\mathrm{P}<0.02)$. On the other hand, the mean weight of the thyroid gland in rats exposed to continuous darkness was significantly reduced from $0.14 \pm 0.13 \mathrm{mg} / \mathrm{g} B$.wt. in the control rats to $0.08 \pm 0.005 \mathrm{mg} / \mathrm{g}$ (Table 1$)$. This reduction $(37.14 \%)$ was statistically significant.

The mean weight of the testes in rats exposed to continuous light was significantly increased $(P<0.001)$ by $41.07 \%$ from $2.8 \pm 0.09 \mathrm{mg} / \mathrm{g}$ to $3.95 \pm 0.075 \mathrm{mg} / \mathrm{g}$ (Table 1). In contrast, the mean weight of the testes in rats exposed to continuous darkness was $1.72 \pm 0.163$ $\mathrm{mg} / \mathrm{g}$ while that of the control rats was $2.8 \pm 0.09 \mathrm{mg} / \mathrm{g} \mathrm{B}$. wt.The $38.75 \%$ reduction in testicular weights between the two groups was highly significant $(P<0.001)$.

TABLE 1: Effects of Continuous Light on The Relative Weights of The Tests and Thyroid Gland

\begin{tabular}{|l|l|l|}
\hline Group & $\begin{array}{l}\text { THYROID GLAND } \\
\text { (mg/g B.W) }\end{array}$ & $\begin{array}{l}\text { TESTES } \\
\text { (mg/g B.W.) }\end{array}$ \\
\hline Control rats $(\mathrm{n}=5)$ & $0.14 \pm 0.13$ & $2.80 \pm 0.09$ \\
\hline $\begin{array}{l}\text { Light -exposed } \\
\text { rats }(\mathrm{n}-5)\end{array}$ & $\begin{array}{l}0.206 \pm 0.01 \\
(+47.14 \%)^{*}\end{array}$ & $\begin{array}{l}3.95 \pm 0.075 \\
( \pm 41.07 \%)^{* *}\end{array}$ \\
\hline $\begin{array}{l}\text { Dark-exposed } \\
\text { rats }(\mathrm{n}=5)\end{array}$ & $\begin{array}{l}0.088 \pm 0.13 \\
(-37.14 \%)^{*}\end{array}$ & $\begin{array}{l}1.72 \pm 0.16 \\
(-38.75 \%)^{* *}\end{array}$ \\
\hline
\end{tabular}

Percentage chages in parenthesis

Serum $\mathrm{LH}$ and FSH : The serum level of $\mathrm{LH}$ for the rats exposed to continuous light was slightly increased by $16.28 \%$ from $2.58 \pm 0.23 \mathrm{mlU} / \mathrm{ml}$ in the control rats to $3.00 .17 \mathrm{mlU} / \mathrm{ml}$ (Table 2). However, this rise was not statistically significant $(P>0.05)$. On the other hand, the serum level of L14, for rats exposed to continuous darkness was $1.52 \pm 0.30 \mathrm{mIU} / \mathrm{ml}$ (Table 2). The difference was statistically significant $(P<0.05)$.

The serum level of $\mathrm{FSH}$ was significantly increased by $84.55 \%$ from $5.18 \pm 0.60 \mathrm{mIU} / \mathrm{ml}$ in the control rats to $9.56 \pm 0.50 \mathrm{mlU} / \mathrm{ml}$ (Table 3 ) in rats kept in continuous light $(\mathrm{P}<0.001)$. In contrast, the senun level of $\mathrm{FSH}$ was slightly reduced by $12.74 \%$ in the rats kept in continuous darkness from $5.18 \pm 0.60 \mathrm{mlU} / \mathrm{ml}$ for the control rats to 4,52 $0.66 \mathrm{mlU} / \mathrm{ml}$ (Table 2). This difference was not significant $(\mathrm{P}>0.05)$.

Serum $T_{4}$ : The serum levels of $\mathrm{T}_{4}$ was significantly increased by $20.69 \% \quad(P<0.02)$ from $87.00 \pm 2.98$ $\mathrm{nmols} / \mathrm{L}$ in the control rats to $105 \pm 4.29 \mathrm{nmols} / \mathrm{L}$ in the rats exposed continuous light (Table3). The serum level of T4 was slightly increased by $14.48 \%$ from $87.00 \pm$ $2.98 \mathrm{mnols} / \mathrm{L}$ in the control to $99.6 \pm 15.89 \mathrm{nmols} / \mathrm{L}$ (Table 4 ) in the rats exposed to continuous darkness. This difference was not significant $(P>0$. 1).

\section{Histology of the Thyroid Gland and Testes}

Plates 1 and 2 show the histological characteristics of the light and dark exposed rats. In the rats exposed to continuous light, the epithelial cells of the thyroid follicles were flattened and the follicles had little or fio colloid. The follicles were larger but fewer than those of the control rats. These are evidences of an active gland. In the rats exposed to continuous knees, the epithelial cells were more columnar than those of the control. The thyroid follicles contained less colloid than-the of the control rats. The follicles were however smaller in size 
African Jurnal of Biomedical Research (2001): Vol. 4/ Olatunji-Bello and Sofola

and were more numerous than those of the control rats This suggests an active gland.

TABLE 2: Effects Of Continuous Light and darkness on Serum Level Of $\mathrm{T}_{4}$. FSH and LH In Rats

\begin{tabular}{|l|l|l|l|}
\hline Group & $\mathrm{T}(\mathrm{nmols} / \mathrm{L})$ & $\begin{array}{l}\mathrm{FSH} \\
(\mathrm{mlU} / \mathrm{ml})\end{array}$ & $\mathrm{LH}(\mathrm{mlU} / \mathrm{ml})$ \\
\hline Control rats & 87.00 & 5.18 & 2.58 \\
$(\mathrm{n}=5)$ & \pm 2.98 & \pm 0.60 & \pm 0.23 \\
\hline Light- & 105.00 & 9.56 & 3.0 \\
exposed rats & \pm 4.29 & \pm 0.50 & \pm 0.17 \\
$(\mathrm{n}=5)$ & $(+20.69 \%)^{\star}$ & $(+84.55 \%)^{\star *}$ & $(+16.28)^{\mathrm{NS}}$ \\
\hline Dark & 99.6 & 4.52 & 1.52 \\
exposed & \pm 5.89 & \pm 0.66 & \pm 0.30 \\
[n=5] & $(+14.48 \%)^{\mathrm{NS}}$ & $(-12.74 \%)^{\mathrm{NS}}$ & $(-41.08 \%)^{\star}$ \\
\hline
\end{tabular}

Percentage chages in parenthesis; NS = Not significant
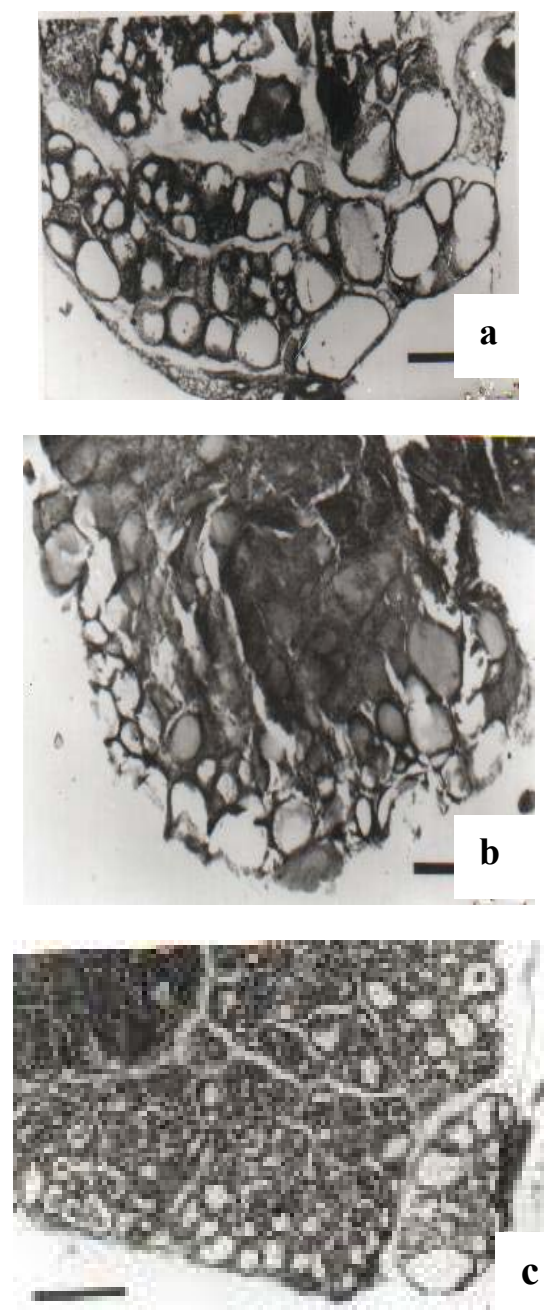

Plate 1: Sections of the thyroid of gland of (a) light exposed rat, (b) Control rat and (c) dark exposed rat. Note absence little or no colloid and colloid as well as flattened epithelial cells in the light-exposed rats. The follicles of control rat thyroid are moderately filled with colloid

The capsule (Tunica albuginae) in the testes of the rats exposed to continuous light was more thickened when compared with that of the control. The interstitial connective tissue of the rats exposed to constant light was larger. The seminiferous tubules were observed to contain more spermatqzoa and they were rather spaced out because of the larger mass of the interstitial connective tissue. The basement membrane and the outer laminae were conspicuously mapppd out in, the rats exposed to light.
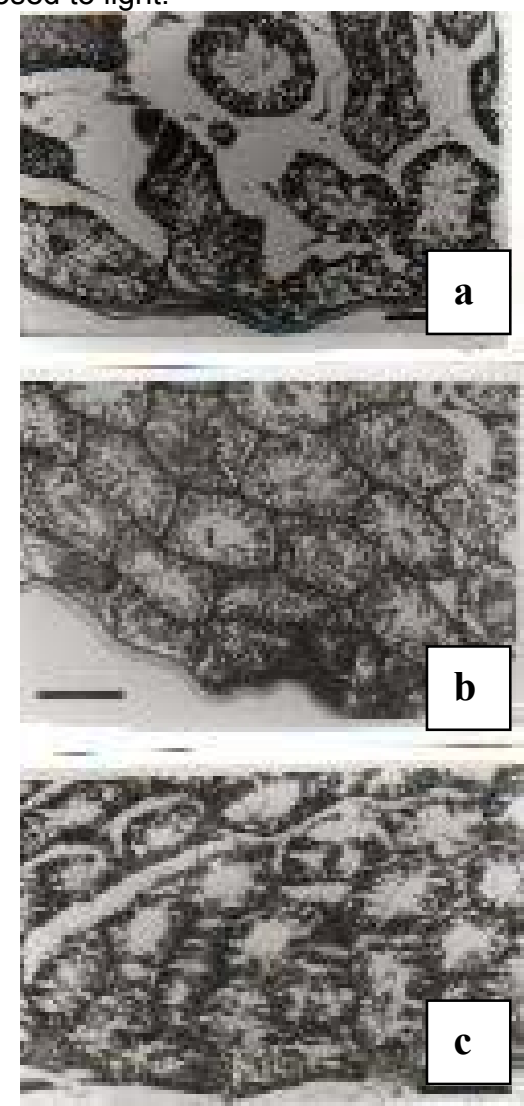

Plate 2: Sections of the testes of (a) light exposed rat, (b) Control rat and (c) dark exposed rat.

In the dark exposed rats, the tunica albuginae (fibrous capsule) was thinned out or almost absent. The lume'ns of the seminiferous tubules were larger than those of the control and they appeared to contain little or no spermatozoa. The tubules were clustered together such that the basement and the outer laminae were almost absent. The interstitial connective tissue was almost not seen. The stage of spermatogenesis could not be identified because the spermatogenic cells and supporting cells of Sertoli were numerous but were clustered together in the testes of the rats exposed to continuous darkness.

\section{DISCUSSION}

From the results of the present study, the size of the thyroid gland was significantly increased. The level of thyroid hormone was also significantly raised. The histological examination showed that the thyroid gland had an increased activity as evidenced by the presence of little or no colloid in the thyroid follicle. Normally during the day, light inhibits the production of melatonin by means of the neural pathway described. Conversely, at night during darkness pineal melatonin production proceeds unabated. 
The almost exclusive production of melatonin at night has given rise to the concept that melatonin is the chemical expression of darkness (Reiter, 1991b). Based on the above statements, the anti thyroid effect of melatonin as observed earlier (Olatunji-Bello and Sofola, 1995) is absent.This explains the observed increased activity of the thyroid gland.

Continuous light exposure resulted in an increase in the size of the testes and elevation of the hormones, $\mathrm{LH}$ and $\mathrm{FSH}$. Since the production of melatonin had been inhibited by light, it is therefore logical that at night, the level of these hormones would be elevated. The effect of this on the testis would therefore be predictable. The observations were expected and are in accordance with the report of Hastings et al (1989). They reported that in hamsters maintained on long photoperiod (I 6 hours of light and 6 hours of darkness), the gonads were larger in size than those maintained at normal lighting rhythm of 12 hours of light and 12 hours of darkness. Our result is also similar to that of Boyd1985) whose studies demonstrated the spontaneous growth of the testes of the rabbits after transfer from short daylength to long daylength. Hastings and others (1989) also showed that serum LH levels were slightly higher in hamsters exposed to long daylength than those exposed to short daylength. Increased levels of LH and FSH would imply more stimulation of the testes leading to the observed increase in size of the gonads and increased spermatogenesis.

Continuous exposure to darkness would'ensure that melatonin production proceeded unabated, The antithyroidi, effect of melatonin (Olatunji-Bello and Sofola, 1995) was expected. However, histological examination showed that thyroid activity was reduced despite the fact that there was a reduction in the size of the gland and little or no change in the serum thyroxine level. We suggest that the observed increased thyroid activity is compensatory.

The antigonadic effect of melatonin was observed in the rats exposed to continuous darkness. Hastings et al (I 989) reported a similar result when they exposed male Syrian hamsters to a short photoperiod of 8 hours of light and 16 hours of darkness for 7 weeks. They found that testicular atrophy was induced and a pronounced suppression of the serum gonadotrophin levels.

Thus exposure of rats to continuous darkness for a period of 6 weeks would result in gonadal regression and anti-gonadotropic effect in the rat.

\section{ACKNOWLEDGEMENTS}

The research was funded by a grant from the CRC of the University of Lagos. The authors appreciate the technical assistance of Dr Banji Adegunloye.

\section{REFERENCES}

Boyd,I.L.(1985).Effectofphotoperiodismandmelatoninontestisde velopmentand regression in wild European rabbit. Biol. Reprod. 33(I): 21 - 29.

Hastings,M.H.,Herbert,J.,Martensz,N.I and Roberts, A.C. (1989) (Annual reproductive rhythms in mammals: mechanisms of light synchronisation. Ann. NY Acad. Sci. 453: 182 - 204.

Olatunji-Bello, 1. 1. and Sofola, 0. A (1995). Effects of daily melatonin injections on the pituitary gonadal axis and thyroid activity in female rats. Nig. J. Physiol. Sci. I 1: $63-66$.

Reiter, R. J. (1991a): Melatonin: that ubiquitously acting pineal hormone. News Physiol. Sci. 6: 223-227.

Reiter, R. J. (1991b) Melatonin: the chemical expression of darkness. Mol. Cell Endocrinol. 79: C 153 - C 159 .

Reiter, R. J. (1991c): Pineal Gland: Interface between the photoperiodic environment and the endocrine system. Trends Endocrinol. Metab. 2: 13 - 19.

Reiter, R. J. (1994): Melatonin: multifacet messenger to the masses. Lab. Med. 25(7): 438 - 443.

Rollag, M. D. and Stetson, M. H. (1986): Ontogeny of the pineal melatonin rhythm in hamsters. Biol. Reprod. 24: 311 314.

Vriend, J. (1981): The pineal and melatonin in the regulation of pituitary-thyroid axis. Life Sci. 29: 1929 - 1936.

Wade, G. N. and Bartness, J. T (1984). Seasonal obesity in Syrian hamsters: effects of age, diet, photoperiod and melatonin and melatonin. Am. J. Physiol. 247, R328 R334.

Received: June 2001

Accepted: September, 2001 